\title{
Disturbed handling of ascorbic acid in diabetic patients with and without microangiopathy during high dose ascorbate supplementation
}

\author{
A.J.Sinclair ${ }^{1}$, A.J.Girling ${ }^{2}$, L. Gray ${ }^{3}$, C.Le Guen ${ }^{3}$, J.Lunec $^{3}$ and A.H.Barnett ${ }^{4}$ \\ Academic Department of ${ }^{1}$ Geriatric Medicine, ${ }^{2}$ Department of Mathematics and Statistics, University of Birmingham, \\ ${ }^{3}$ Department of Biochemistry, Selly Oak Hospital, \\ ${ }^{4}$ Department of Medicine, University of Birmingham and East Birmingham Hospital Birmingham, U. K.
}

Summary. Abnormalities of ascorbic acid metabolism have been reported in experimentally-induced diabetes and in diabetic patients. Ascorbate is a powerful antioxidant, a cofactor in collagen biosynthesis, and affects platelet activation, prostaglandin synthesis and the polyol pathway. This suggests a possible close interrelationship between ascorbic acid metabolism and pathways known to be influenced by diabetes. We determined serum ascorbic acid and its metabolite, dehydroascorbic acid, as indices of antioxidant status, and the ratio, dehydroascorbate/ascorbate, as an index of oxidative stress, in 20 matched diabetic patients with and 20 without microangiopathy and in 22 age-matched control subjects. Each study subject then took ascorbic acid, $1 \mathrm{~g}$ daily orally, for six weeks with repeat measurements taken at three and six weeks. At baseline, patients with microangiopathy had lower ascorbic acid concentrations than those without microangiopathy and control subjects $(42.1 \pm 19.3$ vs $55.6 \pm 20.0, p<0.01$, vs $82.9 \pm 30.9 \mu \mathrm{mol} / 1, p<0.001$ ) and elevated dehydroascorbate/ascorbate ratios $(0.87 \pm 0.46$ vs $0.61 \pm 0.26, p<0.01$, vs $0.38 \pm 0.14, p<0.001$ ). At three weeks, ascorbate concentrations rose in all groups $(p<0.0001)$ and was maintained in control subjects (151.5 \pm $56.3 \mu \mathrm{mol} / \mathrm{l})$, but fell in both diabetic groups by six weeks $(p<0.01)$. Dehydroascorbate/ascorbate ratios fell in all groups at three weeks $(p<0.0001)$ but rose again in the diabetic groups by six weeks $(p<0.001)$ and was unchanged in the control subjects. Dehydroascorbate concentrations rose significantly from baseline in all groups by six weeks of ascorbic acid supplementation $(p<0.05)$. No significant changes were observed in fructosamine concentrations in any group during the study. Diabetes mellitus is associated with a major disturbance of ascorbic acid metabolism which is only partially corrected by ascorbate supplementation.

Key words: Ascorbic acid, dehydroascorbic acid, diabetes mellitus, free radical activity, oxidative stress.
Reduced levels and altered metabolic turnover of ascorbic acid (AA, vitamin C) have been reported in several tissues in experimentally induced diabetes [1-3] and in diabetic patients [4]. There are reports that high dose vitamin C regimens are associated with reversal of early signs of retinopathy [5] and normalisation of capillary strength in diabetes mellitus [6]. In the elderly non-diabetic population AA is often deficient and may be correctable by supplementation [7] - this problem might be of particular significance in elderly diabetic patients who are reported to show more rapid progress of some diabetic complications [8].

Ascorbic acid functions as an important component of cellular defence against oxygen toxicity and lipid peroxidation caused by free radical mechanisms $[9,10]$. During scavenging of free radicals it is converted to dehydroascorbic acid, DHA, in serum and in the mitochondrial fractions of various tissues [11]. It is also a co-factor in the biosynthesis and post-translational modification of collagen due to interaction with proline hydroxylase $[12,13]$, and has been demonstrated to affect immune function [14], platelet activation [15], prostaglandin synthesis [16] and the polyol pathway [3]. These observationssuggest a possible close interrelationship between AA metabolism and pathways known to be influenced by the diabetic process.

Although leucocytes act as a storage reservoir for ascorbic acid and thus are considered by some workers to reflect overall vitamin Cstatus, leucocyte concentrations do not correlate well with intake [17], are technically more difficult to measure, and are subject to a variety of influences such as stress, surgery, tobacco smoking, and exercise [18]. In comparison, plasma and serum ascorbate levels have been shown to reflect metabolic turnover of the vitamin [19], respond more rapidly to supplementation [20], and are relatively simple and convenient to measure. Single measurements of ascorbate in serum and urine for the purpose of assessing vitamin $\mathrm{C}$ status remains of limited value but when measured several times are thought to be a good indicator of tissue concentration [21]. 
Table 1. Clinical characteristics and biochemical measurements at baseline in the diabetic patients and control subjects. Mean (SD)

\begin{tabular}{|c|c|c|c|}
\hline & \multicolumn{2}{|c|}{ Diabetic patients } & \multirow{2}{*}{$\begin{array}{l}\text { Control } \\
\text { subjects } \\
n=22\end{array}$} \\
\hline & $\begin{array}{l}\text { Complica- } \\
\text { tions } n=20\end{array}$ & $\begin{array}{l}\text { No complica- } \\
\text { tions } n=20\end{array}$ & \\
\hline Age (years) & $69.4(8.8)$ & $68.0(8.8)$ & $71.2(5.7)$ \\
\hline Sex (male/female) & 9,11 & 10,10 & 11,11 \\
\hline $\begin{array}{l}\text { Duration of diabetes } \\
\text { (years) }\end{array}$ & $9.3(6.2)$ & $10.4(5.7)$ & \\
\hline $\begin{array}{l}\text { Random glucose } \\
(\mathrm{mmol} / \mathrm{l})\end{array}$ & $12.3(3.9)$ & $9.8(3.7)$ & $4.8(0.7)$ \\
\hline $\begin{array}{l}\text { Serum fructosamine } \\
(\mathrm{mmol} / \mathrm{l})\end{array}$ & $2.09(0.3)$ & $1.88(0.3)$ & $1.73(0.2)$ \\
\hline $\begin{array}{l}\mathrm{AA} \\
(\mu \mathrm{mol} / \mathrm{l})\end{array}$ & $42.1(19.3)^{\mathrm{a}}$ & $55.6(20.0)$ & $82.9(30.9)$ \\
\hline $\mathrm{DHA}(\mu \mathrm{mol} / \mathrm{l})$ & $31.3(9.9)$ & $30.5(10.8)$ & $28.8(12.6)$ \\
\hline DHA/AA ratio & $0.87(0.46)^{\mathrm{b}}$ & $0.61(0.26)$ & $0.38(0.14)$ \\
\hline
\end{tabular}

${ }^{a}$ Patients with complications had significantly lower ascorbic acid (AA) than patients without $(p<0.01)$ and both groups had lower concentrations than control subjects $(p<0.001$ and $p<0.01$, respectively).

b Patients with complications had greater dehydro-ascorbic acid (DHA)/AA ratios than patients without $(p<0.05)$ and both groups had higher ratios than control subjects ( $p<0.01$ and $p<0.05$, respectively)

In addition, the ascorbic acid content of polymorphonuclear leucocytes has been shown to correlate positively with plasma concentration [22].

We have studied the relationship between serum AA (and its metabolite dehydroascorbic acid, DHA) and the presence of microangiopathy in a group of elderly Type 2 (non-insulin-dependent) diabetic patients. The effects of six weeks AA supplementation on serum AA and DHA concentrations are also reported.

\section{Subjects and methods}

Twenty Type 2 diabetic patients with retinopathy and 20 without any evidence of complications were studied. All subjects were over 60 years of age and had been diabetic for at least two years. They were attending the outpatient department of East Birmingham Hospital. Retinopathy was defined on the basis of funduscopic examination through dilated pupils by the presence of any of the following: haemorrhage, exudate, microaneurysm or proliferation. The 20 patients without complications had no evidence of microvascular disease (fundi normal on funduscopic examination of the dilated eyes, no proteinuria on albustix testing, normal serum urea and creatinine, and no clinical signs of peripheral neuropathy). The examination was carried out by two experienced observers.

All patients were normotensive for their age and had no major evidence of macrovascular disease (no relevant history, palpable foot pulses, normal ECG). Each had normal serum albumin and haemoglobin concentrations. Four patients with and three patients without microangiopathy were being treated with insulin; the rest were treated with dietary instruction and/or oral hypoglycaemic agents. Three patients in each group smoked cigarette tobacco.

Twenty two age-matched control subjects (11 male, 11 female) were recruited from the local community. None had any significant history of treatment for hypertension. None were cigarette tobacco smokers but two subjects smoked pipe tobacco.

The clinical characteristics of the patients and control subjects are given in Table 1. Based on initial plasma levels of ascorbic acid none of the control subjects were overtly nutritionally-deficient in this vitamin. One month prior to entry into the study subjects underwent dietary assessment and were asked not to take added vitamin supplements. Diabetic patients were all following a high fibre, low fat diet. The subjects were seen on three study days: at entry, and at three and six weeks after oral vitamin C supplementation ( $1 \mathrm{~g}$ daily) to their diet. No subjects defaulted from the study, and no illness or adverse effects were recorded.

Venous blood was taken from each subject approximately 1.5$2 \mathrm{~h}$ after breakfast on each study day. Subjects took their regular daily dose of vitamin $\mathrm{C}$ after blood sampling on the three and six week study days. Venous serum was separated from each blood sample by centrifugation immediately after venepuncture. An aliquot of serum was vortex mixed with an equal volume of $10 \%$ metaphosphoric acid (MPA) and was centrifuged for $7 \mathrm{~min}$ at $3,500 \mathrm{~g}$ at $4^{\circ} \mathrm{C}$. The supernatant was decanted and stored at $-70^{\circ} \mathrm{C}$ for less than one week to enable assays to be analysed in single batches. Ascorbic acid and dehydroascorbic acid were measured on the supernatant by HPLC by a modification of a previous method developed in this laboratory [23]. Addition of EDTA and gassing with nitrogen, precautions which were previously undertaken to prevent oxidation of AA to DHA in the MPA-extracted samples, were omitted since we observed negligible conversion of AA to DHA in their absence (unpublished data). We further modified our methodology by substituting methanol/water as the mobile phase with acetonitrile, disodium phosphate buffer, and a small percentage of glacial acetic acid; this combination produces im-

Table 2. Biochemical measurements in control subjects $(n=22)$ and diäbetic patients (complications (MA) $n=20$; No complications (No MA) $n=20$ ) prior to (time 0 ) and at three and six weeks following ascorbic acid supplementation. Mean (SD)

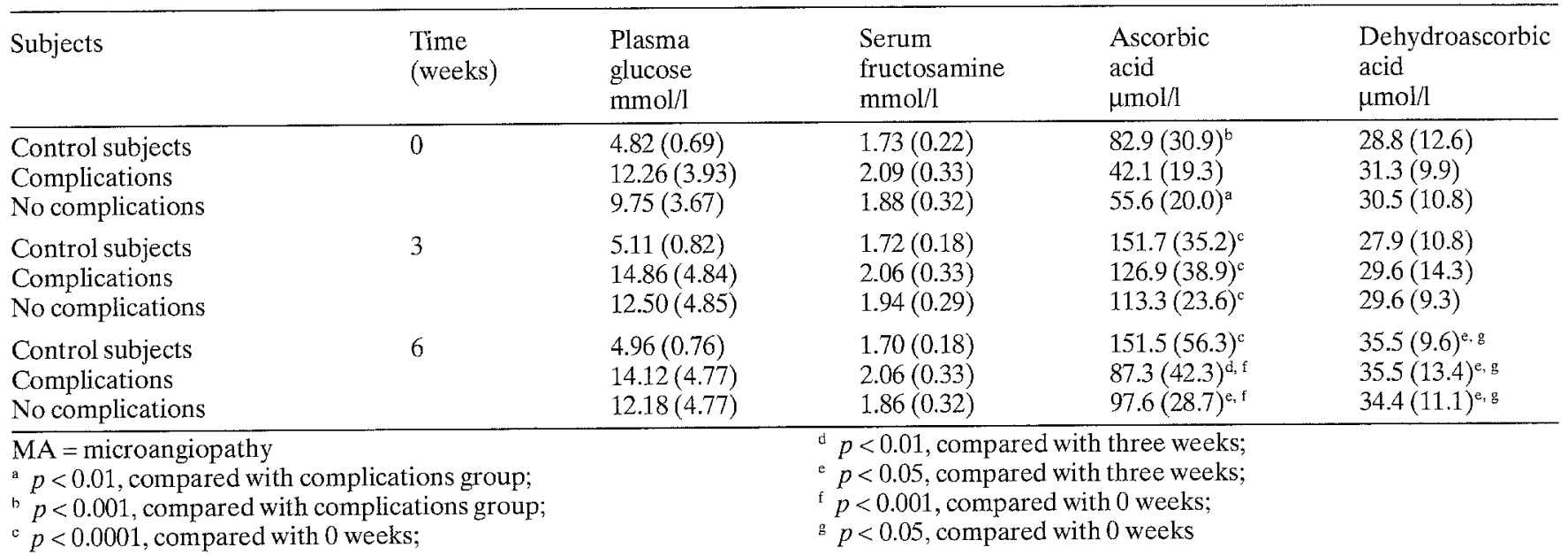


<smiles>COC(O)C1OC(=O)C(O)=C1O</smiles><smiles>[2H]C(Cl)(Cl)[Cl+3]([O-])([O-])[O-]</smiles>

Fig. 1. Molecular structures of L-Ascorbic acid and D-Glucose

proved chromatographic separation of ascorbic acid and its metabolites.

Ascorbate was measured by ultraviolet absorption at $254 \mathrm{~nm}$, and dehydroascorbic acid as its fluorescent $\mathrm{O}$-phenylenediamine derivative (ex $360 \mathrm{em} 455 \mathrm{~nm}$ ) [23]. The within batch coefficient of variation, (CV) was $3.1 \%$ for $\mathrm{AA}$, and $4 \%$ for DHA, and the between batch $\mathrm{CV}$ was $3.8 \%$ for $\mathrm{AA}$, and $4.5 \%$ for DHA.

Glucose was measured using a glucose oxidase method and fructosamine was measured as previously published (within batch $\mathrm{CV}$ for the assay, $1.5 \%$, between batch $\mathrm{CV}, 3.0 \%$ ) [24]. The measured concentrations of AA and DHA were used as indices of antioxidant status, and the ratio DHA/AA was used to give an index of the degree of oxidation occurring to $\mathrm{AA}$ in the serum (oxidative stress).

After approval for the study from the local hospital Ethics Committee both patients and control subjects gave individual, informed written consent to participate.

\section{Statistical analysis}

Baseline data were analysed by non-parametric procedures (MannWhitney U test; Kruskal-Wallis analysis). A repeated measures analysis of variance was applied to each variable for the AA supplementation phase of the study. Results are expressed as means \pm SD.

\section{Results}

At baseline, patients with microangiopathy (MA) had significantly lower concentrations of AA compared with those without MA $(p<0.01)$ who in turn had significantly lower concentrations of AA than control subjects $(p<0.01)$. Patients with MA had significantly elevated DHA/AA ratios compared with those without MA $(p<0.01)$ and control subjects $(p<0.001)$. No significant differences were seen in DHA concentrations between the groups and the diabetic groups did not differ significantly in serum fructosamine concentrations (Table 1).

After AA supplementation, concentrations of AA rose significantly $(p<0.0001)$ at three weeks in all groups (Table 2) reaching a mean peak concentration of 151.7 , 113.3 , and $126.9 \mu \mathrm{mol} / 1$ in the control subjects, diabetic patients without MA, and diabetic patients with MA, respectively $(p<0.01$, control subjects vs the group with MA and the group without MA).

After six weeks of AA supplementation, the mean concentration of AA was maintained in the control group but fell in both diabetic groups ( $p<0.01$, MA group; $p<0.05$, no MA group). These concentrations, however, were still significantly higher than at baseline $(p<0.001)$.

The DHA/AA ratios (Fig. 2) fell significantly in all groups at three weeks after AA supplementation $(p<0.0001)$. At six weeks the mean DHA/AA ratio rose significantly in both diabetic groups $(p<0.001)$ but remained unchanged in the control subjects. The DHA/AA ratios still remained significantly lower than at baseline $(p<0.001)$ in all groups.

Concentrations of DHA rose significantly from baseline by six weeks of AA supplementation $(p<0.05)$.

The plasma concentrations of glucose did not significantly alter during the study in the control group but rose in both diabetic groups by three weeks $(p<0.02)$ and then showed a non-significant fall at six weeks. There were no significant changes in serum fructosamine concentrations in any of the groups during the study.

\section{Discussion}

We found reduced concentrations of $\mathrm{AA}$ and increased oxidative stress (as evidenced by elevated DHA/AA ratios) in a group of elderly Type 2 diabetic patients when compared with an age-matched non-diabetic control group. These abnormalities were more pronounced in those patients with microangiopathy. This latter observa-

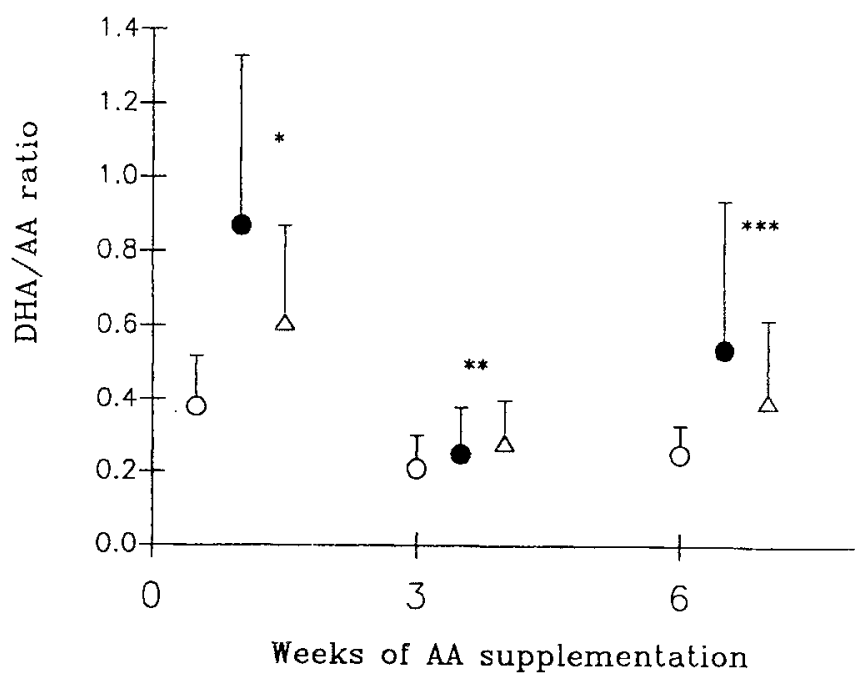

Fig. 2. Dehydroascorbic acid/ascorbic acid (DHA/AA) ratios in diabetic patients ( $=$ with complications, $\triangle=$ no complications) and in control subjects $(O)$ at baseline $(0$ weeks) and during ascorbic acid supplementation. Mean ( \pm SD bars).

* patients with complications had greater DHA/AA ratios than patients without $(p<0.01)$ and both groups had higher ratios than control subjects $(p<0.001$ and $p<0.01)$, respectively).

** $p<0.0001$, compared with the DHA/AA ratios at

0 weeks (all groups).

***: $p<0.001$, compared with three weeks (diabetic groups only). Ratios remained significantly lower $(p<0.001)$ than at baseline (0 weeks) in all groups 
tion is contrary to our previous findings of a trend towards higher ascorbate concentrations in patients with retinopathy [25]. However, in this former study, the differences were not statistically significant, the patients studied were much younger, were both Type 1 (insulin-dependent) and Type 2 (non-insulin-dependent), and were not matched for disease duration.

Low concentrations of AA in diabetes are probably due to a high metabolic turnover [4] reflecting increased consumption of AA by oxidation to DHA. These observations could be related to the free radical scavenging (antioxidant) role of AA $[9,10]$ and increased free radical activity has been previously demonstrated in diabetes $[26$, 27]. In an earlier study we suggested that free radical mechanisms might be implicated in the development of microangiopathy [28].

Studies using human lymphocytes suggest that competitive inhibition between glucose and ascorbic acid, which have structural similarities (Fig.1), for transport across the cell membrane may be one mechanism for our finding of low concentrations of AA in diabetic sera [29]. Similar effects of glucose analogues (3-O-methylglucose/2-deoxyglucose) on the in vitro uptake of DHA by polymorphonuclear leucocytes and fibroblasts have been described [30]. A recent study has also demonstrated prompt intracellular depletion of AA in human mononuclear leucocytes following an intravenous glucose tolerance test [31]. We could not, however, demonstrate a relationship between AA and glycaemic control suggesting that lowered AA concentrations in diabetic patients are not a direct consequence of hyperglycaemia. This is in agreement with a previous study [4] but in another study an inverse relationship between plasma $\mathrm{AA}$ and glycosylated haemoglobin was reported [3].

The lack of a significant difference in DHA concentrations between control subjects and diabetic patients is in accord with previous studies $[32,33]$, but contrary to earlier reports of elevated DHA in Indian diabetic patients $[4,34]$. This discrepancy is unlikely to be due to differences in type or severity of diabetes since DHA concentrations (without ascorbic acid supplementation) are not related to treatment, duration of illness or blood glucose concentrations [4]. Other workers calculated DHA as total vitamin $\mathrm{C}$ minus measured $\mathrm{AA}$. This method ignores the contribution of diketogluconic acid, a breakdown product of AA. We separately measured AA and DHA using a sensitive HPLC method [23] and therefore avoided this error.

After AA supplementation in control subjects serum concentrations of AA rose significantly by three weeks and were maintained at this level at six weeks. Similarly, there was a significant rise in AA concentrations at three weeks (although peak concentrations were significantly lower than in control subjects) in both diabetic groups, but in striking contrast to the control subjects, concentrations of AA fell significantly in all patients by six weeks despite continued AA supplementation. These data suggest a major defect in ascorbic acid metabolism in diabetes which is unlikely to be related to glycaemic control as this did not alter significantly during the study. Furthermore, this metabolic defect appears to be common to all patients with diabetes irrespective of whether or not they have microvascular complications.

A recent study was unable to demonstrate excessive loss of urinary ascorbic acid in diabetic patients [35], but AA supplementation in our study might have created an exaggerated loss before homeostatic compensation occurred. It has already been estimated that the body pool size of AA is about $1500 \mathrm{mg}$ and that orally administered vitamin $\mathrm{C}$ appears in the urine only when this limit has been reached or exceeded [36].

The significant fall in DHA/AA ratios in all groups during the first three weeks of ascorbate supplementation implies a striking reduction in oxidative stress reflecting the role of AA as an important antioxidant. The more pronounced fall in the ratios in the diabetic patients compared with the control subjects may be due to tissue ascorbate deficiency in diabetes [1] with a consequent rapid uptake of AA via metabolism to DHA. The rise in the DHA/AA ratios in the diabetic groups after six weeks of AA supplementation provides additional evidence for a disturbance in AA metabolism in diabetes. This might be related to a 'pro-oxidant' action of AA (that is, promotes lipid peroxidation) when a critical concentration of AA is reached and maintained $[37,38]$. This in vivo concentration is not known with certainty but might vary between diabetic patients and normal subjects.

Concentrations of DHA rose in all subjects after six weeks AA supplementation irrespective of whether the subject was diabetic or not. We cannot explain why DHA concentrations were not higher at three weeks in view of the large doses of AA given but DHA accumulation may just be a general metabolic response to AA loading and indicate stochiometric conversion of AA to DHA and not due to any specific differences in AA metabolism or impairment of DHA uptake or excretion. Our data did not confirm the view that DHA has an independent diabetogenic action [39].

We conclude that patients with Type 2 diabetes demonstrate a significant disturbance in the metabolic handling of ascorbic acid. The biological importance of these observations remains unclear and requires further investigation from longer term controlled trials of vitamin C supplementation in patients with diabetes mellitus.

\section{References}

1. Yew MS (1983) Effect of streptozotocin diabetes on tissue ascorbic acid and dehydroascorbic acid. Horm Metab Res 15: 158

2. Rikans LE (1981) Effect of alloxan diabetes on rat liver ascorbic acid. Horm Metab Res 13:123

3. Yue DK, McLennan S, Fisher E, Heffernan S, Capogreco C, Ross GR, Turtle JR (1989) Ascorbic acid metabolism and the polyol pathway. Diabetes 38: 257-261

4. Som S, Basu S, Mukherjee D, Deb S, Choudary R, Mukherjee S, Chatterjee SN, Chatterjee IB (1981) Ascorbic acid metabolism in diabetes mellitus. Metabolism 30: 572-577

5. Crary EJ, McCarty MF (1984) Potential clinical applications for high dose nutritional antioxidants. Med Hypothesis 13: 77-98

6. Cox BD, Butterfield WJH (1975) Vitamin C supplements and diabetic cutaneous capillary fragility. Br Med J 3: 205

7. Neale RJ, Lim H, Turner J, Freeman C, Kemm JR (1988) The excretion of large vitamin Cloads in young and elderly subjects: an ascorbic acid tolerance test. Age Ageing 17:35-41 
8. Caird FI (1982) Complications of diabetes in old age. In: Evans JG, Caird FI (eds) Advanced geriatric medicine. Pitman, London, pp 3-9

9. Procter PH, Reynolds ES (1984) Free radicals and disease in man. Physiol Chem Phys 16: 175-195

10. Levine M (1986) New concepts in the biology and biochemistry of ascorbic acid. N Engl J Med 314: 892-902

11. Siperstein MD, Unger RH, Madison LL (1968) Studies of muscle capillary basement membranes in normal subjects, diabetic and pre-diabetic patients. J Clin Invest 47:1973-1999

12. Barnes MJ (1976) Function of ascorbic acid in collagen metabolism. Ann NY Acad Sci 258: 264-275

13. McLennan S, Yue DK, Fisher E, Capogreco C, Heffernan S, Ross GR, Turtle JR (1988) Deficiency of ascorbic acid in experimental diabetes: relationship with collagen and polyol pathway abnormalities. Diabetes 37: 359-361

14. Pecoraro RE, Chen MS (1987) Ascorbic metabolism in diabetes mellitus. In: Burns JJ, Rivers JM, Machlin LJ (eds) Third Conference on Vitamin C. Ann NY Acad Sci 498: 248-258

15. Sarji KE, Kleinfelder J, Brewington P, Gonzalez J, Hempling H, Colwell JA (1979) Decreased platelet vitamin Cin diabetes mellitus: possible role in hyperaggregation. Thromb Res 15: 639-650

16. Lands WEM, Letellier PR, Rome LH, Vanderhork JY (1972) Inhibition of prostaglandin biosynthesis. Adv Biosci 9: 15

17. Garry PJ, Vanderjagt DJ, Hunt WC (1987) Ascorbic acid intakes and plasma levels in healthy elderly. In: Burns JJ, Rivers JM, Machlin LJ (eds) Third Conference on Vitamin C. Ann NY Acad Sci 498: 90-99

18. Omaye ST, Schans EE, Kutnink MA, Hawkes WC (1987) Measurement of vitamin $C$ in blood components by high performance liquid chromatography. In: Burns JJ, Rivers JM, Machlin LJ (eds) Third Conference on Vitamin C. Ann NY Acad Sci 498: 389-401

19. Sauberlich HE, Green MD, Omaye ST (1982) Determination of ascorbic acid and dehydroascorbic acid. In: Seib PA, Tolbert BM (eds) Advances in chemistry. American Chemical Society. Washington DC, pp 199-221

20. Omaye ST, Skala JH, Jacob RA (1986) Plasma ascorbic acid in adult males: effects of depletion and supplementation. Am J Clin Nutr 44: 257

21. Moser U (1987) Uptake of ascorbic acid by leucocytes. In: Burns JJ, Rivers JM, Machlin LJ (eds) Third Conference on Vitamin C. Ann NY Acad Sci 498: 200-215

22. Evans RM, Currie L, Campbell A (1982) The distribution of ascorbic acid between various cellular components of blood in normal individuals, and its relationship to the plasma concentration. Br J Nutr 47: 473-482

23. Lunec J, Blake DR (1985) The determination of dehydroascorbic acid and ascorbic acid in the serum and synovial fluid of patients with rheumatoid arthritis. Free Rad Res Comm 1: 31-39

24. Jones AF, Winkles JW, Thornally PJ, Lunec J, Jennings PE, Barnett AH (1987) Inhibitory effect of superoxide dismutase on fructosamine assay. Clin Chem 22: 147-149
25. Jennings PE, Chirico S, Jones AF, Lunee J, Barnett AH (1987) Vitamin $C$ metabolites and microangiopathy in diabetes mellitus. Diabetes Res 6: 151-154

26. Nath N, Chari SN, Rathi AB (1984) Superoxide dismutase in diabetic polymorphonuclear leucocytes. Diabetes 33:586-589

27. Collier A, Wilson R, Bradley H, Thompson JA, Small M (1990) Free radical activity in type 2 diabetes. Diabetic Med Jan 7:27-30

28. Jennings PE, Jones AF, Florkowski CM, Lunec J, Barnett AH (1987) Increased diene conjugates in diabetic subjects with microangiopathy Diabetic Med 4: 452-456

29. Davis KA, Lee WYL, Labbé RF (1983) Energy dependent transport of ascorbic acid into lymphocytes. Fed Proc 42: 2011

30. Bigley R, Wirth M, Layman D, Riddle M, Stankova L (1983) Interaction between glucose and dehydroascorbate transport in human neutrophils and fibroblasts. Diabetes 32:545-548

31. Chen MS, Hutchinson ML, Pecoraro RE, Lee WYL, Labbe RF (1983) Hyperglycaemia-induced intracellular depletion of ascorbic acid in human mononuclear leucocytes. Diabetes 32: 1078-1081

32. Newill A, Habibzadeh N, Bishop N, Schorah CJ (1984) Plasma levels of vitamin $\mathrm{C}$ components in normal and diabetic subjects. Ann Clin Biochem 21: 488-490

33. Stankova L, Riddle M, Larned J, Burry K, Menashe D, Hart J, Bigley R (1984) Plasma concentrations and blood cell dehydroascorbate transport in patients with diabetes mellitus. Metabolism 33: 347-353

34. Banerjee A (1982) Blood dehydroascorbic acid and diabetes mellitus in human beings. Ann Clin Biochem 19: 65-70

35. Yue DK, McLennan S, Mcgill M, Fisher E, Heffernan S, Capogreco C, Turtle JR (1990) Abnormalities of ascorbic acid metabolism and diabetic control-differences between diabetic patients and diabetic rats. Diab Res 9: 239-244

36. Kallner A, Hartmann D, Hornig D (1979) Steady-state turnover and body pool size of ascorbic acid in man. Am J Clin Nutrit 32: 530-539

37. Wills ED (1985) The role of dietary components in oxidative stress in tissues In: Sies H (ed) Oxidative Stress. Academic Press, New York, pp 197-218

38. Wayner DDM, Burton GW, Ingold KU (1986) The antioxidant efficiency of vitamin $\mathrm{C}$ is concentration dependent. Biochim Biophys Acta 884: 119-123

39. Patterson JW (1950) The diabetogenic effect of DHA and dehydroisoascorbic acid. J Biol Chem 183: 81-88

Received: 21 November 1989

and in final revised form 10 September 1990

Dr. A.J. Sinclair

Academic Department of Geriatric Medicine

Selly Oak Hospital

Raddlebarn Road

Birmingham B26 $6 \mathrm{JD}$

UK 